\title{
Challenges in Transdisciplinary, Integrated Projects: Reflections on the Case of Faculty Members' Failure to Collaborate
}

Linda Vanasupa • Kathryn E. McCormick •

Carolyn J. Stefanco • Roberta J. Herter •

Margot McDonald

\begin{abstract}
In this article we describe the challenges of transdisciplinary teamwork involving four faculty members from dissimilar epistemological traditions in the process of developing a manuscript on the lessons learned in our teaching collaboration. Our difficulty originated in implicit mental models and assumptions that caused incongruence between our intent to collaborate and the (habituated) relationship structure of the partnership. The dynamics are described through the lens of Tannenbaum and Schmidt's leadership model and Aristotle's
\end{abstract}


causality. We suggest that successful collaboration necessitates careful attention to the process of establishing the collaboration, its structure, and the metacognitive capacities to see one's own thinking, suspend one's epistemic beliefs, and engage in productive dialogue around conflict.

The United States is largely led by recipients of college degrees. It is not surprising, then, that in light of our growing systemic challenges and social inequities, leaders from within academia have wondered aloud if institutions of higher education are fulfilling their social contract with the public (Bok 2006; Lewis 2006; Niemann and Maruyama 2005). One such group, convened by the Association of American Colleges and Universities, went beyond wondering to define a new meaning for higher education in our world of ever-increasing complexity. Its views, developed through a multilayered dialogue dating from 2000 and with hundreds of institutions involved, are captured in the National Leadership Council for Liberal Education \& American's Promise report, College Learning for the New Global Century (Association of American Colleges and Universities 2007). It is commonly referred to as "The LEAP Report" in reference to the title of the initiative, Liberal Education \& America's Promise (LEAP). This report is an attempt to consider the competencies and skills necessary for a citizen of the 21st century. In concert with those engaged in the business community (Savage et al. 2007), the authors of the report called attention to the high level of fragmentation within organizations and its detriment to deep approaches to learning and collaboration across disciplines. The authors articulated the growing consensus in academia that,

The traditional boundaries between the liberal arts and the professional fields are not just a bureaucratic inconvenience. In practice, they have created academic silos that impede faculty and staff efforts to foster a more holistic and integrative approach to college learning. (2007, p.13).

The LEAP Report advocated for change through high-impact, integrative practices such as interdisciplinary modes of learning. While there are studies examining the potential for transformational change through interdisciplinary education, many focus on the institutional barriers and opportunities that exist for individuals, departments, and the institution as a whole (Holley 2009; Stone et al. 2009).

This call for integrative approaches to education is not new. In Petrie's 1992 review of interdisciplinary education, he cited John Dewey's attacks on narrow disciplinary formulation, dating back to the early twentieth century. Petrie also differentiated among multidisciplinarity, interdisciplinarity, and transdisciplinarity approaches. One of the features he identified is the extent to which integration of knowledge occurs. Petrie considered multidisciplinary efforts as a kind of "group work" that draws on different disciplines usually for the purpose of solving a specific problem, whereas the goal of interdisciplinarity is the integration of the different views. What is implicit in Petrie's reference to both multidisciplinary and interdisciplinary 
approaches is that they derive from disciplines with a common epistemic view. The reported practice of interdisciplinary education (e.g., Feisel and Rosa 2005; Hornsey et al. 2008; Lattuca et al. 2004; Peterson 2008) often confirmed this unexamined assumption: as reported, interdisciplinarity involved individuals from disciplines with common beliefs about the nature of knowledge and the methods of acquiring knowledge. The vision of the LEAP Report, however, seemed to call for an educational approach that transcends epistemic paradigms. This approach would be more closely aligned with transdisciplinarity (Després et al. 2004; Petrie 1992; Klein 2004). Transdisciplinary approaches allow for multiple, co-existing viewpoints and utilize the discontinuities between views as a source for further inquiry and emergent understanding. These approaches also support the systemic collaboration needed to address complex societal challenges (Senge et al. 2007).

However, advocacy of transdisciplinary, integrated approaches often focuses on the learning benefits without a serious consideration of the current ecology within higher education; our institutions and their faculties are organized to support differentiated disciplinary specialties. How then do we create transdisciplinary experiences together out of our separated disciplinary cultures? What are the risks for both faculty members and students? What are the conditions under which these integrated learning environments enable all to thrive? What are the attributes of projects that will serve the development of students and faculty? What skills are needed by the faculty members to enable the success of the transdisciplinary projects?

We do not intend to answer these important questions in full; however, we have uncovered some answers through an analysis of our failed transdisciplinary effort to collaborate.

\section{The Case Study}

In the context of this case study, "failure" refers to the authoring faculty members' inability to collaboratively create our intended, idealized manuscript product in a timely fashion. By "collaboration" we mean a mode of group work in which individuals are equally engaged in the group's activities as co-creators. We focus on the faculty members and the institutional ecology of the failure and illustrate how the same dynamics were at play within the student project. The faculty members candidly reflected on the challenges they encountered in their transdisciplinary collaboration to produce the intended manuscript nearly 3 years after the collective decision to do so. While this length of time is explained, in part, by factors that influence academic life, the faculty collaboration both embodied the disciplinary perspectives and mirrored the challenges reported by the students who completed their 10-week transdisciplinary, integrated class project in 2007.

Using the methods of first person research and action inquiry, we examined the implicit assumptions, mental models, and structural features that contributed to the collapse of the faculty collaboration for timely dissemination. We note that the inquiry around the failure of the collaboration emerged from the conflict experienced by the faculty members at the point of collapse (December 2009). The authors position themselves as research subjects and critically reflect on their biases and difficulties in the collaborative process. This deeper reflection is retrospective, as we neither anticipated our failure nor explicitly committed to this level of inquiry at the outset of the post-project analysis. As in all action research, this analysis applies to a unique situation.

The case study, a useful approach to social inquiry where data are unique and persistent (Yin 1981, 1994; Stake 1995), emerged from the faculty members' (Herter, McCormick, Stefanco and Vanasupa) attempt to analyze and disseminate what was learned through the experience of the class project. It involved our analysis of a series of post-project 
reflections, student interview transcripts, critical discussions of events leading up to the class project collaboration, and attempts to write about its outcomes. The authors explored the dynamic that developed in the transdisciplinary collaboration. We relied on Stake's concept of "boundedness" to translate our disciplinary behavior patterns in terms of broader institutional features affecting the outcomes of the collaboration (Stake 1978, 1995). The case study method of Ragin (1992) helped us see beyond the limits of our individual disciplines. Using Bohm's (1985) method of unfolding meaning allowed us to make explicit the barriers for transdisciplinary collaboration and to recognize the value of developing the case. As has been reported by Lele and Norgaard (2005), the barriers included the value-laden nature of inquiry, differences in methodology and epistemology, and the larger societal values that were reflected within the collaborative dynamic. However, it is not the existence of these necessary dimensions of transdisciplinary work that is problematic; we suggest that it is their unexamined nature coupled with a lack of awareness of how to resolve differences that undermines this kind of collaboration.

For this article, we drew upon the leadership pattern proposed by Tannenbaum and Schmidt (1958) as an organizing framework to make explicit the implicit and often unintended social hierarchy that can occur in the process of collaborating. We describe the features of the transdisciplinary project through the lens of Aristotle's four types of causality to illuminate our choices and their consequences. These features along with the faculty members' lack of facility with their own mental models and lack of capacity to engage in constructive cross-model conversations ultimately disabled our ability to collaborate effectively. We summarize what we learned about the conditions for successful transdisciplinary learning with respect to faculty leadership. We also recommend ways in which we have since begun to build the capacity to work constructively with conflict, drawing upon the work of Bohm (1996) and Kuhn on paradigm shifts (1970). We focus on the challenges in the faculty collaboration, which turned out to reflect the student challenges. We believe that a greater awareness of these patterns and a greater capacity for constructively utilizing them would facilitate more successful transdisciplinary projects.

We begin by describing the institutional context for the collaboration. This is followed by a detailed description of the collaboration; a discussion of the challenges; and, finally, our recommendations to overcoming these challenges.

\section{The Institutional Setting}

There has been a significant focus on the role of institutional leadership in organizational change and organizational learning (Bensimon and Neumann 1993; Senge et al. 1994; Duderstadt 2000; Boyce 2003). Clearly, the ways in which leaders interact with their institutions profoundly influence institutional cultures and subsequent institutional patterns of behavior. In the same way, we posit that a transdisciplinary classroom setting can embody a microcosm of the larger institutional dynamics (Newell 1992, 1998). Institutions often develop hegemonic political cultures with privilege residing in disciplines that utilize quantitative ways of knowing (Greenwood and Levin 2005; Minnis and John-Steiner 2005). Within the campus culture at comprehensive universities, some report that the liberal arts have frequently had difficulty in securing their identity beyond that of a service organization to the professional colleges (Boix-Mansilla et al. 2000; Brint et al. 2008).

Our case study took place at a polytechnic state institution focused on undergraduate education in the western United States, which we will call "Western Polytechnic University" (WPU). WPU has a rich tradition of experiential learning, and courses are 
expected to have practical significance. Academic programs are organized into six different colleges: Liberal Arts, Science and Mathematics, Architecture, Business, Agriculture, and Engineering. The enrollment in the professional colleges, which are all but Liberal Arts and Science and Mathematics, constitutes about $75 \%$ of the roughly 20,000 students.

WPU's historical culture can be described as hegemonic with the professional colleges implicitly holding more power. At the time of this study, there was a strong perception that Engineering had privileged status on campus as evidenced by newer facilities and industrysponsored laboratories. This perception is reified by the larger U.S. cultural value system, which reflects a higher market value for professions like engineering through larger salaries. For example, according to a survey of U.S. employers (PayScale 2010), engineering disciplines were seven of the top ten college majors that lead to high salaries. The other three majors on this list were Computer Science, Economics, and Physics - all disciplines with epistemologies that rely heavily on quantitative data.

Like many institutions, the colleges at WPU are quite distinct and separated. Faculty offices are clustered by department, and the buildings generally house departments belonging to a single college. The Department of Graphic Design is an exception to this rule, as it shares a building with the College of Architecture. The curricular structure reinforces these divisions; and, not surprisingly, team teaching, particularly across departments and colleges, is discouraged by a workload reporting policy that penalizes the faculty members involved by distributing the weighted teaching units across the faculty team. The difficult work of team teaching then counts as a smaller workload for the faculty involved. Nevertheless, there are a few mechanisms created to enable more accurate accounting for the workload involved in team teaching at WPU. One program, for example, requires that faculty members compete with one another for the additional resources to ensure that both instructors of a team-taught course earn full unit credit, thereby further undermining efforts to build social fabric across departmental and college boundaries.

Discussions about the revision of general education and major requirements are often highly politicized in this climate, and curricular changes are usually enacted in the absence of meaningful input from the departments that would be significantly affected. These patterns of behavior underscore the fragmented nature of WPU. Those who work across disciplinary boundaries do so at their own peril as there are no systemic incentives to do so.

We must also point out that the WPU culture has been historically strained by issues of gender inequity. We note that less than $20 \%$ of faculty members of the Engineering College are female, whereas the College of Liberal Arts has a higher proportion (roughly 35\%) of female faculty members. Of the six colleges, only one has a female dean, and she leads the College of Liberal Arts. Within the last few years the only other college led by a woman (The College of Education) was discontinued. At no time in its over 100-year history, has there been a female in leadership in the executive suite of WPU. This large imbalance of gender representation at all levels of the upper administration speaks to the masculine nature of the culture, if only by the numbers. This institutional history is relevant to this case study because it was the cultural ecology in which the case study was situated. As asserted by organizational behavior researchers like Schein (1985), individuals are both enactors and victims of the organizational cultural dynamics that they inhabit.

\section{The Project}

The process of creating the class project created an implicit leadership dynamic that would ultimately undermine the faculty collaboration. We describe this process using the 
leadership framework first proposed by Tannenbaum and Schmidt (1958), who were primarily speaking to a business audience. They described a continuum of relationships that a "leader" could choose to have with their "subordinates." This continuum, later adapted by Senge et al. (1994), depicts a leadership continuum ranging from an autocratic relationship with "subordinates" on the left where decision-making control resides in the "leader" to a democratic relationship on the right where the decision-making power resides in the collective. Senge et al. (1994) conceived of the different styles of leadership from least to most democratic as "tell" (autocratic), "sell", "test," "consult" and "collaborate." These leadership styles represent different balances of power between the leader and the group. In moving from the autocratic models on the left to democratic on the right, there is an increased requirement for individuals in the group to manage different viewpoints in the decision-making process.

The transdisciplinary integrated class project had been initiated by an Engineering faculty member in an effort to serve the goals of a grant to improve engineering education (Vanasupa 2010). The engineering students in this particular course were in the first cohort of students to be exposed to a conversion of their required engineering courses from a lecture-based format to a project-based format with a strong emphasis on self-directed learning. This conversion has been described elsewhere (Savage et al. 2007). The project was part of a junior-level course, team taught by a female and a male faculty member who had equal responsibilities for the management and teaching of the course. This course involved 12 hours per week of face-to-face class time, which reflected about half of the engineering students' curricular requirements for that quarter. The project established by the female faculty member was intended to account for roughly half of the grade for the course.

The female faculty member established the scope of the transdisciplinary integrated project in consultation and with a female architecture faculty member. On Tannenbaum and Schmidt's continuum, this leadership transaction represented a "consult" and "test" dynamic. The architecture faculty member was working to obtain funding to restore a historical building on campus for student club use. The student project work had the potential to be integrated into a proposal to a funding agency for the implementation of the project. Based on the constraints of the engineering course (33 engineering students), the two faculty members decided to create 11 teams that would submit competing proposals. The architecture faculty member then sought institutional partners for the project teams. In the process of getting faculty partners, she presented the idea in a "selling" mode to history and graphic design faculty members. These two faculty members then agreed to be involved in the project for the purpose of strengthening the professional competencies of their history and graphic design students. Administratively, the participation of the faculty members was accounted for differently. It was part of the engineering faculty member's regular course workload, part of a displaced workload for the architecture faculty member, and part of an overload for the history and graphic design faculty members. Note that the engineering faculty member presented the project to the engineering students in the "tell" model of leadership. To the students, it was an assignment in which their autonomy was confined to the design project. So the initial beginnings of the project tended toward the autocratic end of Tannenbaum and Schmidt's leadership continuum. The history and graphic design faculty members presented the project to the history and graphic design students who were participating in the project in the "sell' model of leadership. While several different models of leadership were active ("Tell", "Sell", "Consult" and "Test"), none of the initial dynamics were genuinely collaborative. In other words, the culture and structure of the "collaboration," was in fact non-collaborative. Our attempted collaboration was unconsciously created in a way that established an implicit and unexamined hierarchy. 
This simple fact would ultimately contribute to the inability of the faculty members to work together effectively in the preparation of this article.

\section{Cause of Collaboration Difficulties}

For clarity, we used Aristotle's causality (Falcon 2011) as a framework for differentiating the sources of the authors' difficulty in collaborating. His analysis of a particular outcome included four origins that he called material cause, efficient cause, formal cause, and final cause. These domains are pictured in Fig. 1 as conceptualized by Burton and Vanasupa (2009). The material cause refers to the physical components of which something is made. In our case, one might call the web-based collaboration tools, a material cause. The efficient cause refers also to the physical way in which processes interact with the material. For the authors, the efficient cause would refer to the manner in which the faculty members gathered and analyzed data and communicated information. The formal cause begins to consider relationships and refers to the design of activities - the goals and organization of the individuals within the collaboration. In our case, individuals had several goals upon entering the attempted collaboration, most of which had not been explicitly considered beforehand. The final cause refers to the intent behind all actions, primarily expressed within the mental models of the individuals involved. As in the case with the goals, the mental models for many elements of the original classroom project and post-project analysis were unexamined. They varied across and within the two groups involved, i.e., the students and the faculty members. These included mental models of one another, of how a project should be completed, of the value of each disciplinary perspective, and of the decision-making process. As illustrated and labeled in Fig. 1, each causality derives from a cognitive frame of reference, or mental model of change. For the material and efficient causes, the model of change is one of manipulating physical objects to produce the desired effect, i.e., a subject-object frame of reference. Burton considers the top half to be areas where one's primary attention is on the relationships while the bottom half refers to a focus on the physical and material elements.

Ideally, a creative endeavor would begin with a clear intent (final cause) followed by a design that proceeds from that intent (formal cause), clockwise in Fig. 1. Processes

Fig. 1 Aristotle's causalities. Reconceived by Roger Burton (Burton and Vanasupa 2009)

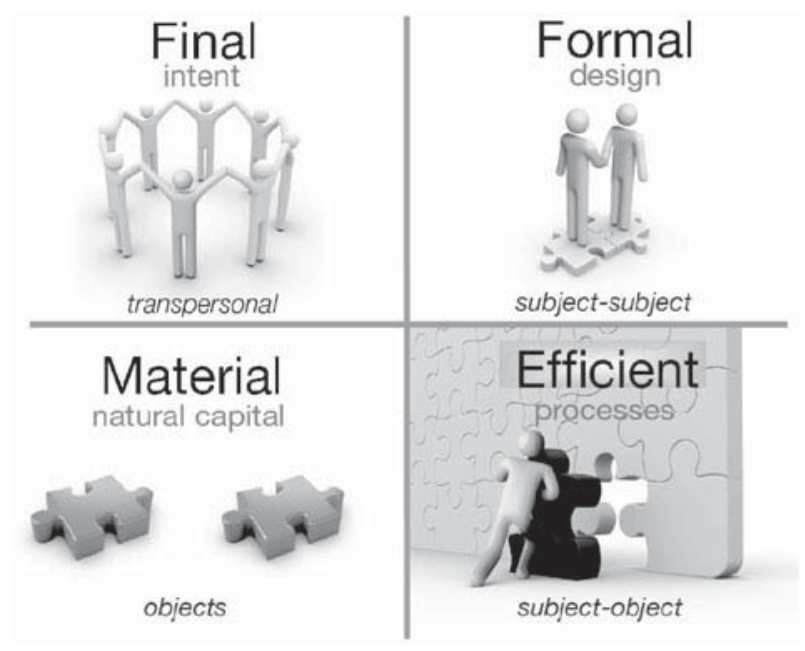


(efficient cause) and physical logistics (materials cause) would be the last to be specified since they are chosen to serve the final cause. When we reflected on our collaboration, we realized that there had been little consideration given to both final and formal causes. The faculty members focused on processes and logistics, habitually chosen out of our unexamined presumptions. In other words, our attention was on the material domain, the bottom half of Fig. 1.

As noted earlier, the faculty members involved in the project represented four disciplinary cultures. In a real but unconscious way, they held very different beliefs about teaching, learning, the nature of knowledge, the methods of gaining understanding, interactions with students, and management of the project. For example, engineers exhibit dualistic (i.e., right and wrong) ways of viewing the world as evidenced by development studies of engineering students (Jehng et al. 1993; Paulsen and Wells 1998; Pavelich and Moore 1996; Wise et al. 2004). Historians, on the other hand, appreciate the socially constructed nature of individual and group experience and seek "to understand difference by giving it a history" (Scott 1996, p.7). These assumptions about viewpoint result in very different dispositions in the face of conflict.

Each of our disciplinary habits strongly shaped the structure and dynamics of the entire attempted collaboration. However, at the beginning of the class project, we, the faculty members, did not explicitly acknowledge our differences. Our focus was on functioning in a way that we assumed would enable the students to complete the course requirements. In retrospect, our failure to state and examine our assumptions directly was the largest source of conflict for students in the class project and for us in the process of examining the subsequent data.

For example, an implicit hierarchy developed within the group, with the engineering faculty member being the implied client and the other faculty members assuming a role of service to her. This happened, we believe, because the project was established out of our unconscious cultural habits of relating. As we have already explained, the project was initiated through transactions in which the participants "bought into" the process with individualized expectations of return on their investments. A true collaboration requires individuals to relate as equal co-creators with shared goals, rather than contracted agents who are serving someone else's goals in exchange for a personal gain. At the time the project started, the engineering faculty member did not possess the awareness or level of distinction necessary to discern the unexamined ways in which she was leading the project. Neither did the other faculty members possess the required understanding or the ability to articulate the dynamic. A service role was perhaps quite natural for the graphic design and architecture faculty members as these fields both involve interactions with clients. As stated in the section titled "The Institutional Setting," a subordinate role was also the perceived institutional dynamic of Liberal Arts in relationship to Engineering with individuals in both colleges engaging in actions that perpetuate the dynamic. In retrospect, the history and engineering faculty members recognized that they were participating in this dynamic of dominance. In short, the shared faculty mindset around the class project "collaboration" was transactional rather than co-creative in nature. The architect was provided with release time for her role as client by grant funding from the engineer; prior to initiating the class work, the architect and engineer conferred on the constraints and requirements of the class project with no input from others. The historian and the graphic designer "bought into" the project on the basis of its potential to provide exposure to transdisciplinary and integrated project-based learning for their students.

The structure of the dynamic relationships of the would-be collaborators falls within the category of formal cause. Without explicit consideration of final or formal cause, the form 
of the relationships defaulted to cultural habits of relating. As previously explained, the culture at WPU is hierarchical rather than collaborative. However, this dynamic was more or less beneath the level of awareness for those involved in the project. In reference to Tannenbaum and Schmidt's (1958) model of leadership, the hierarchical nature of the project was built into the structure in the way in which the faculty related to one another in establishing the project. In their model, the use of authority by the "manager" ranges from autocratic to democratic. In between these two extremes are varying ways that the "manager" can transfer autonomy and decision-making power to others. This occurs through seeking input from others. Collaboration requires a co-creative relationship between "leader" and "subordinates," in the language of Tannenbaum and Schmidt. While the engineering faculty member intended to collaborate, the structural relationship among the faculty members was established largely through the "sell" dynamic to the history and graphic design colleagues, in which people enter the project not as true collaborative partners but as those who are giving something in exchange for some perceived value that they have "bought". Students and the male engineering colleague were subjected to a "tell" mode of leadership. One consequence of this mode is that those on the receiving end of being told are far less likely to be personally invested in the success of the collaborative work. Evidence of this can be seen in the fact that the male engineering colleague, who was not technically responsible for the project, entirely disengaged from the project within two weeks. A collaborative mode, by contrast, occurs through full intellectual participation. The class project and the subsequent faculty research did not successfully transition from a transactional model to a collaborative model during the class project or the subsequent data analysis by faculty members.

Through the lens of Aristotle's causality, we see that the initiator of the project, the female engineering faculty member, was chiefly concerned with dimensions of the project in the efficient and material causes. She created the scope of the project in consultation with the architecture faculty member from a mechanistic, engineering mental model to fit the educational needs of the funding agency. In this model, her priority was in designing a project that called on the expertise of each of the different students, but she did not realize there was an opportunity to co-create the project with the other faculty members or students. From a philosophical standpoint, the engineering faculty member was unconsciously interacting with others in the project as objects to be used in service to the learning goals. In contrast, an approach that considers people as "subjects" includes the learner's feelings, interests, and values in the process, rather than fixing primary dimensions prior to consulting. This subject-object orientation was consistent with the type of thirdperson research approaches used in fields like Engineering and the physical sciences. Its consequence in a human system is that those who are told what must be done are denied autonomy of choice. This lack of autonomy depletes one's intrinsic motivation to engage in an activity and pushes one toward external motivators of engagement (Deci and Ryan 2000). In extreme cases, people can experience a disconnect between their valued outcomes and what they believe they are required to do. According to Deci and Ryan (1985), this situational motivational state is called "amotivation" and is evidenced by statements such as "I don't know why I am doing this, but I am," and "I can't see the point in what we are doing." In "amotivation," individuals' attention shifts away from participating because they value it and toward participating in order to gain an external reward or avoid a punishment. They experience a complete disconnect between their own goals and what they are doing. An approach to the project where all parties are relating to one another as individuals with interests, feelings, and values of equal legitimacy to their own would have begun with an invitation to co-create the goals, form, and structure of the project. While there was not 
open conflict about the implicit roles, the implicit subordinate roles subtly undermined the effectiveness of the collaboration within the faculty and student groups. Very simply, a hierarchical structure inhibits collaborative functioning

After the completion of the class project, which occurred in 2007 , the faculty members attempted to collaborate on the analysis of the research data, including a retrospective look at the students' experience. At the time, we neglected to consider seriously the ways in which we as faculty members had influenced the students' experience. In short, we were ill prepared for the high-level of self-awareness needed to work effectively with conflict and engage in cross-disciplinary conversations. The most dramatic evidence of this fact is that it has taken nearly three years for us to document our work to share with the larger higher education community. In a real way, our difficulty in preparing this article is a microcosm of the difficulties faced by the students in the course of their 11-week long project. Students and faculty members alike struggle to come together constructively out of the disciplinary habits of work and mind that they have developed. We note that these differences were largely invisible to us prior to the attempted collaboration. They only surfaced in the process of attempting to collaboratively complete the manuscript on the student classroom project.

For example, the engineering and graphic design faculty members have professional habits that involve meeting client-established goals, objectives, and deadlines. They acted in ways that were consistent with that worldview. This meant setting up the classroom project in a way that articulated the "deliverables" of the student projects in terms of the functional requirements of the projects. In the language of design, functional requirements articulate performance criteria that the projects must satisfy. We approached the authoring of this manuscript in largely the same way, with the history faculty member originally requesting to serve as the lead author, after the initial data analysis was led by the engineering faculty member from June 2007 to March 2008. In 2008, the history faculty member left WPU for a position at another institution. From March 2008 through August 2009, there was little progress made on the manuscript. The group reconvened in September 2009 to complete the manuscript at the engineering faculty member's request. In her role as lead author, the history faculty member made requests of her co-authors for research, information, and reflective pieces. It may be important to note that the engineering faculty member established the virtual collaboration space for the work without consulting the others. From the outset, the history faculty member stated her discomfort with the technology that was being used for the collaborative space, but her suggestions for using regular email were largely dismissed as insufficient for the nature of the work by the engineering and graphic design faculty members. The collaboration was clearly not working between individuals separated by hundreds of miles with intense professional responsibilities at different institutions. The engineering faculty member's failure to consult the others in choosing the mode of collaboration for writing this article, and in choosing to invite an additional collaborating researcher after the class project, was further evidence of the implicit hierarchy within the faculty team.

In many ways, disciplinary specialization promotes autonomy and requires a kind of individualism. It is our experience that, in disciplines based in the physical sciences like engineering, curricula are presented as a "fact-based" worldview rather than as a relativistic and interpretive one. This often leads to a habitual conflation of one's perspective as fact. In other words, individuals educated into disciplines based in the physical sciences have been taught that the nature of their knowledge is that it is "factual," "real," and "true." This disposition can inhibit learning that involves a significant shift in perspective since this type of learning comes about through resolving conflict between an observed reality and one's 
current point of view (Johnson and Johnson 1989). Furthermore, because our disciplinary lives are highly developed, challenges to our viewpoints are often perceived as challenges to our professional identity, so conversations that involve conflict with what occurs to one person as a "fact" may strike that same person as a direct challenge to that same person's identity.

One of the ways that this perceptual confusion surfaced within the project is through the conflict around timeline and disciplinary methods of research. About 18 months after the historian had offered to serve in the role of lead author, she described in a conference call that the normative process of research in her field involved a thorough investigation of all possibly relevant information, much of which might not be used in the process of formulating the historical analysis. This process was described as typically taking 10 years to complete for a book project. This was the first instance of any of the authors explicitly stating their conceptions of the research process. While this divergent intellectual process is not unlike the initial stages of design for engineers and designers, the engineering and graphic design co-authors did not want to participate in a process that occurred to them as inefficient and beyond what they perceived as the "conventional" time limits for completion. This difference of view about the collaborative project timeline became a source of contention that we could not unpack without emotionally-charged conflict which we were unprepared to address.

Without personal awareness of one's own mental models, one's viewpoint can be inadvertently conflated with personal identity. One then often habitually defends personal views with the vehemence with which existence would be defended. This unexamined integration of viewpoint with personal identity is often at the heart of a conflict, which cannot be worked through constructively without self-awareness in the moment that it is occurring. Additionally, academic environments like the one at WPU are perceived to require people to assert and demonstrate their disciplinary expertise. This promotes the need to be "right" rather than the possible admission to "not knowing." A disposition of "not knowing" is required for learning. Therefore, academic cultures, by discouraging a disposition of "not knowing" at times inhibit learning by faculty members.

We note that our attention was on completing an idealized version of a product from our work together. This focus and attention on a final product was mimicked by the student groups during the class project. In retrospect, greater attention should be placed on the process of learning. This would include an expectation of conflict and possible failure to produce the product. A greater focus on the process of collaboration would free all to learn from the conflicts rather than find ways to avoid them. We suggest that those who would like to undertake similar collaborations consider gaining personal and group facility with forms of inquiry that promote self-reflection and embrace conflict as integral to the process of learning. One such research method is action research, in which the researchers consider themselves as subjects in the phenomena that are being studied. This form of inquiry seeks to generate integrity within ourselves through a continual inquiry into the gaps between one's thoughts, actions, and intended outcomes (Torbert 2004).

\section{Conclusion}

Our retrospective self-examination of this transdisciplinary collaboration revealed many individual decisions that contributed to our inability to collaboratively produce this article in the intended timeframe. The student teams within the classroom project that initiated the faculty collaboration mirrored the same challenges found in the faculty dynamics. While we 
could list the several factors that contributed to our inability to reach our collaborative goals, we assert that the cause of our failure can be traced to not directly and explicitly examining our mental models and our intent for the work together. Out of these unexamined mental models, all decisions were made in a more or less habitual fashion, which consequently replicated the systemic, unhealthy dynamics of our institutional setting. These included hierarchical relationships rather than collaborative ones. They also included a focus on producing a product rather than an emphasis on the process of collaborating across disciplines. While all authors are female, it is also possible that issues of gender inequity were at play, given the history of WPU. While we assert that the institutional culture contributed negatively to the faculty dynamic, we recognize that we are participating and producing that culture. That is, the culture is a product of our own individual and shared actions, for which we are responsible. However, without a greater personal awareness of our unexamined habits of being, these actions go largely unnoticed and experienced as "the way things are" rather than as something we are enacting.

To summarize, for those who desire to create the conditions for successful transdisciplinary work, we recommend that the process of establishing the collaboration embody the dynamics desired within the collaboration itself:

- Prior to the initiative, ensure that collaborators possess a praxis of self-reflection about their own learning, epistemic viewpoints, and mental models. This practice increases the possibility that they will learn together throughout the process.

- Establish collectively shared intent and expected outcomes for students and faculty in the course within the collaborative team. Return to these shared aspirations recursively and examine whether or not decisions align with them.

- Allow the collaborative team to create the form or structure of the collaboration after the intent has been established (including roles and responsibilities). Prioritize egalitarian forms of responsibility rather than hierarchical.

- Give attention to processes and physical elements of the collaboration only after the intent and form have been constituted. Continue to examine the processes and physical elements in light of the shared aspirations to ensure that they are congruent with one another.

- Practice (or develop) the skills to monitor the group's own progress and growth throughout the term and to work with conflict. Embrace conflict as the visible sign of differences in hidden assumptions and mental models. Allow the conflict to serve as the entry point into exploring each others' views.

In many ways, disciplinary identity directly opposes transdisciplinary collaboration through the habits of mind that it instills. A disciplinary viewpoint by definition is a set of identifiable ways of knowing, views of reality, individuation, and methods for understanding. Transdisciplinary work will necessarily involve differences of viewpoint. However, these differences are largely invisible because they are embedded in the intellectual habits gained through our disciplinary enculturation. It is the working together that surfaces these hidden differences and enables the individuals involved to deconstruct the nature of their own viewpoints.

Key competencies for transdisicplinary education, then, include a welcoming disposition toward conflict as an opportunity for learning and the capacity to work constructively with conflict in a group setting. Indeed, conflict is a necessary ingredient for deep learning that requires a shift in one's truths (Johnson and Johnson 1989), so our normal socialization to avoid it has the unintended consequence of undermining the learning process. The process 
of understanding another viewpoint requires one to intellectually and genuinely suspend their personal conceptualization as described by Bohm (1996). In the absence of suspension, groups are left to simply reassert their differences more strongly until they have "won" the argument, or to "compromise" in their views. Bohm asserted that a third option, reliant upon suspending one's views, is the emergence of a new, collective understanding. Additionally, we recommend considering the process of action inquiry or participatory action research. In our view, these forms of research involve the habits of recursive reflection, inquiry, action, and analysis required to work constructively with the unforeseen in the dynamic human system of the transdisciplinary context. These methods of inquiry also include the possibility of apparent "failure" or deviation from the expected result. In the domain of action research, failures are greeted as opportunities to discover elements of the work that one has not accounted for in the original conception.

Acknowledgements This work was supported in part by grants from the National Science Foundation (NSF-EEC\#0834959, NSF-DUE\#0717428). All views are those of the authors and do not necessarily reflect those of the National Science Foundation. The authors thank the students who participated in the research and Roger Burton for his valuable insights.

\section{References}

Association of American Colleges and Universities. (2007). College learning for the new global century: A report from the National Leadership Council for Liberal Education and Americas' Promise. Washington, DC: Association of American Colleges and Universities.

Bensimon, E. M., \& Neumann, A. (1993). Redesigning collegiate leadership: Teams and teamwork in higher education. Baltimore, MD: The Johns Hopkins University Press.

Bohm, D. (1985). Unfolding meaning: A weekend of dialogue with David Bohm. New York, NY: Routledge. Bohm, D. (1996). On dialogue. New York, NY: Routledge.

Boix-Mansilla, V., Miller, W. C., \& Gardner, H. (2000). On disciplinary lenses and interdisciplinary work. In S. Wineburg \& P. Grossman (Eds.), Interdisciplinary curriculum: Challenges to implementation (pp. 1738). New York, NY: Teachers College Press.

Bok, D. (2006). Our underachieving colleges. Princeton, NJ: Princeton University Press.

Boyce, M. (2003). Organizational learning is essential to achieving and sustaining change in higher education. Innovative Higher Education, 28(2), 119-136.

Brint, S., Cantwell, A. M., \& Hanneman, R. A. (2008). The two cultures of undergraduate academic engagement. Research in Higher Education, 49(5), 383-402.

Burton, R., \& Vanasupa, L. (2009). Aristolés causalities. Unpublished diagram.

Deci, E. L., \& Ryan, R. M. (1985). Intrinsic motivation and self-determination in human behavior. New York, NY: Plenum.

Deci, E. L., \& Ryan, R. M. (2000). The "what" and "why" of goal pursuits: Human needs and the selfdetermination of behavior. Psychological Inquiry, 11(4), 227-268.

Després, C., Brais, N., \& Avellan, S. (2004). Collaborative planning for retrofitting suburbs: transdisciplinarity and intersubjectivity in action. Futures, 36(4), 471-486.

Duderstadt, J. J. (2000). A university for the 21st century. Ann Arbor, MI: The University of Michigan Press.

Falcon, A. (2011, Spring) Aristotle on causality, The Stanford encyclopedia of philosophy, Edward N. Zalta (Ed.), Retrieved June 20, 2011 from http://plato.stanford.edu/archives/spr2011/entries/aristotle-causality/

Feisel, L., \& Rosa, A. (2005). The role of the laboratory in undergraduate engineering education. Journal of Engineering Education, 94(1), 121-130.

Greenwood, D. J., \& Levin, M. (2005). Reform of the social sciences and of universities through action research. In N. K. Denzin \& Y. S. Lincoln (Eds.), Handbook of qualitative research (3rd ed., pp. 43-64). Thousand Oaks, CA: Sage Publications.

Holley, K. A. (2009). Interdisciplinary strategies as transformative change in higher education. Innovative Higher Education, 34(5), 331-344. 
Hornsey, M. J., Gallois, C., \& Duck, J. M. (2008). The intersection of communication and social psychology: Points of contact and points of difference. Journal of Communication, 58(4), 749-766.

Jehng, J., Johnson, S. D., \& Anderson, R. C. (1993). Schooling and students' epistemological beliefs about learning. Contemporary Educational Psychology, 18(1), 23-35.

Johnson, D., \& Johnson, R. (1989). Cooperation and competition: Theory and research. Edina, MN: Interaction Book Co.

Klein, T. (2004). Prospects for transdisciplinarity. Futures, 36(4), 515-526.

Kuhn, T. S. (1970). The structure of scientific revolutions (2nd ed.). Chicago, IL: Chicago University Press.

Lattuca, L. R., Voigt, L. J., \& Fath, K. Q. (2004). Does interdisciplinarity promote learning? Theoretical support and researchable questions. The Review of Higher Education, 28(1), 23-48.

Lele, S., \& Norgaard, R. B. (2005). Practicing interdisciplinarity. BioScience, 55(11), 967-975.

Lewis, H. (2006). Excellence without a soul: How a great university forgot education. New York, NY: PublicAffairs.

Minnis, M., \& John-Steiner, V. (2005).The challenge of integration in interdisciplinary education. In E.G. Creamer and L.R. Latucca (Eds.), Advancing Faculty Learning Through Interdisciplinary Collaboration. New Directions for Teaching and Learning, 2005 (102), pp. 45-61. San Francisco, CA: Jossey-Bass.

Newell, W. H. (1992). Academic disciplines and undergraduate interdisciplinary education: Lessons from the School of Interdisciplinary Studies at Miami University, Ohio. European Journal of Education, 27(3), 211-222.

Newell, W. H. (1998). Professionalizing interdisciplinarity. In W. H. Newell (Ed.), Interdisciplinarity: Essays from the literature (pp. 529-563). New York, NY: College Board.

Niemann, Y., \& Maruyama, G. (2005). Inequities in higher education: Issues and promising practices in a world ambivalent about affirmative action. Journal of Social Issues, 61(3), 407-426.

Paulsen, M. B., \& Wells, C. T. (1998). Domain differences in the epistemological beliefs of college students. Research in Higher Education, 39(4), 365-384.

Pavelich, M. J., \& Moore, W. S. (1996). Measuring the effect of experiential education: Using the Perry model. Journal of Engineering Education, 85(4), 287-292.

PayScale (2010, June 6). Best undergraduate college degrees by salary. The PayScale Report,. Retrieved from http://www.payscale.com/best-colleges/degrees.asp

Peterson, V. V. (2008). Against interdisciplinarity. Women and Language, 31(2), 42-50.

Petrie, H. (1992). Interdisciplinary education: Are we faced with insurmountable opportunities? Review of Research in Education, 18, 299-333.

Ragin, C. C. (1992). Cases of “What is a case?". In C. C. Ragin \& H. S. Becker (Eds.), What is a case? Exploring the foundations of social inquiry (pp. 1-18). Cambridge, UK: Cambridge University Press.

Savage, R., Chen, K. C., \& Vanasupa, L. (2007). Integrating project-based learning throughout the undergraduate engineering curriculum. Journal of Science, Technology, Engineering and Math Education, 8(5-6), 1-13.

Schein, E. H. (1985). Organizational culture and leadership. San Francisco, CA: Jossey-Bass.

Scott, J. W. (1996). Feminism and History. New York, NY: Oxford University Press.

Senge, P. M., Lichtenstein, B. B., Kaeufer, K., \& Bradbury, H. (2007). Collaborating for systemic change. MIT Sloan Management Review, 48(2), 44-53.

Senge, P. M., Roberts, C., Ross, R. B., Smith, B. J., \& Kleiner, A. (1994). The fifth discipline fieldbook: Strategies and tools for building a learning organization. New York, NY: Doubleday.

Stake, R. E. (1978). The case study method of social inquiry. Educational Researcher, 7(2), 5-8.

Stake, R. E. (1995). The art of case study research. Thousand Oaks CA: Sage.

Stone, T., Bollard, K., \& Harbor, J. M. (2009). Launching interdisciplinary programs as college signature areas: An example. Innovative Higher Education, 34(5), 321-329.

Tannenbaum, R., \& Schmidt, W. H. (1958). How to choose a leadership pattern. Los Angeles, CA: University of California.

Torbert, W. R. (2004). Action inquiry. San Francisco, CA: Berrett-Koehler.

Vanasupa, L. (2010). The human dimension of systemic department-level change: A change agent's retrospective on a case reform. Advances in Engineering Education.

Wise, J., Lee, S. H., Litzinger, T. A., Marra, R. M., \& Palmer, B. (2004). A report on a four-year longitudinal study of intellectual development of engineering undergraduates. Journal of Adult Development, 11(2), $103-110$.

Yin, R. K. (1981). The case study as a serious research strategy. Science Communication, 3(1), 84-100.

Yin, R. K. (1994). Case study research: Design and methods. Thousand Oaks, CA: Sage. 